Paula C. Casarini, Priscila L. Farias

\title{
Didactica - Tipografia para livros didáticos infantis
}

\author{
Didactica - Typography for children's didactic books
}

Tipografia, design de livros, universo infantil.

\begin{abstract}
Este artigo resume os resultados de um trabalho de conclusão de curso que teve como objetivo o desenvolvimento de uma tipografia para livros didáticos recomendados para crianças em processo de alfabetização, entre 7 e 8 anos. Supõe-se que o emprego de tal tipografia facilite o processo de leitura para a criança, tornando mais sutil a inclusão de livros didáticos ao seu cotidiano, o que pode resultar em incentivo à prática da leitura. A metodologia envolveu pesquisas sobre alfabetização e livros didáticos infantis, além da análise de outras tipografias desenvolvidas para crianças.
\end{abstract}

Com base nas pesquisas e análises, foi desenvolvida uma nova fonte, sem serifa, e com características peculiares, apresentada ao longo desse trabalho.

Typography, book design, infant universe.

This paper summarizes the results of an undergraduate final research that aimed to the development of a typeface for didactic books recommended for children in the process of literacy, between 7 and 8 years. It is believed that the use of such typeface facilitates the process of reading to children, making subtler the introduction of didactic books to their daily lives, which can result in encouraging the practice of reading. The methodology research on literacy and children's textbooks, as well the analysis of other typefaces developed for children.

Based on the research and analysis, a new sans-serif typeface, with peculiar features, was developed, and is presented throughout this work.

\section{Alfabetização}

Na sociedade em que vivemos, apropriar-se da linguagem escrita pode significar uma futura interação social para as crianças, além de uma notável conquista de autonomia. Sobre a importância da aquisição da escrita na fase pré-escolar, Vygotsky (1991, apud Simões, 2000) ressalta que a escrita, ensinada nos anos pré-escolares, é imposta como relevante à vida. As letras se tornam elementos essenciais, como a fala. Com a mesma capacidade que as crianças aprendem a falar, elas aprendem a ler e a escrever.

Para Cagliari (2003), a leitura é um processo de decifração e codificação. O leitor deverá, em primeiro lugar, decifrar a escrita para depois entender a linguagem encontrada, em seguida decodificar todas as implicações que o texto tem e, finalmente, refletir sobre isso e formar o próprio conhecimento e opinião a respeito do que leu. Abud (1987) confirma que é entre os 6 e 7 anos que a criança está preparada fisiologicamente para o aprendizado da escrita, dominando o movimento dos músculos maiores e menores, assim como os movimentos oculares, o que determina que a sua percepção viso-motora é igual à de um adulto. Porém, a alfabetização não é exclusiva da $1^{\mathrm{a}}$ série do ensino escolar, devendo, pois, se estender e consolidar ao longo das séries posteriores.

\section{Livros didáticos infantis}

Segundo Soares (2002), o livro didático surgiu como complemento aos livros literários e tornou-se um instrumento pedagógico que, além de possibilitar o processo intelectual, "contribui para a formação social e política do indivíduo" (Soares, 2002). Para ele, é muito importante que o material 
didático ganhe tanto em qualidade, quanto na sua forma e conteúdo. Para que isso aconteça, editoras especializadas se empenham em projetos gráficos eficazes, aprimorando os conceitos e possibilitando integração nos aspectos gráficos e editoriais.

Dados divulgados pela Câmara Brasileira do Livro demonstram que livros didáticos representam a maior parte do mercado editorial, e que este normalmente oscila entre variações positivas e negativas em relação ao ano anterior. Tal oscilação pode ser atribuída, por dedução, ao reaproveitamento de materiais em escolas públicas brasileiras. Outro fator importante é que o Ensino Fundamental é responsável pelo maior número de exemplares vendidos no ano de 2002 (Câmara Brasileira do Livro, 2002).

\section{Parâmetros tipográficos para livros infantis}

Muitas dúvidas surgem acerca das necessidades infantis quando se pensa em projetos de livros infantis. Segundo Coutinho \& Silva (2007), a coerência com os padrões e recomendações de legibilidade e ergonomia é essencial para o devido aproveitamento do conteúdo informacional de um livro. Eles apresentam alguns desses aspectos que são relevantes para o livro indicados para crianças. Um projeto gráfico bem elaborado deve levar em consideração o público-alvo a que é destinado. No caso de um livro, a idade do leitor é muito importante.

Burt (1959, apud Coutinho \& Silva, 2007) estabeleceu padrões referentes aos tamanhos do corpo da tipografia de acordo com a idade (Tabela 1). Segundo Coutinho \& Silva (2007), para as crianças com menos de nove anos, o ideal são palavras com bem espacejadas, o que pode implicar na melhor compreensão do conteúdo.

Tabela 1: parâmetros gráficos referentes à tipografia propostos por Burt (1959). (Coutinho \& Silva, 2007: 7)

\begin{tabular}{l|l|l|l|l}
$\begin{array}{l}\text { Idade } \\
\text { (anos) }\end{array}$ & $\begin{array}{l}\text { Corpo } \\
\text { (pontos) }\end{array}$ & $\begin{array}{l}\mathbf{N}^{\circ} \text { de letras por linha } \\
\text { (linha com 10,16 cm) }\end{array}$ & $\begin{array}{l}\text { Coluna } \\
\text { (cm) }\end{array}$ & $\begin{array}{l}\text { Entrelinha } \\
\text { (cm) }\end{array}$ \\
\hline Menor que 7 & 24 & 32 & 12.7 & 0.66 \\
\hline $7-818$ & & 38 & 10.16 & 0.432 \\
\hline $8-916$ & & 45 & 8.89 & 0.406 \\
\hline $9-1014$ & & 52 & 9.52 & 0.33 \\
\hline $10-1212$ & & 58 & 10,16 & 0.305 \\
\hline Maior que 12 & 11 & 60 & 11.43 & 0.204 \\
\hline
\end{tabular}

Em relação às variações tipográficas em livros, Walker (1992, apud Coutinho \& Silva, 2007) menciona que isso pode ser benéfico à criança, pois quando esse contato ocorre nos primeiros anos de alfabetização, faz com que ela fique mais ciente e confortável ao encontrar no cotidiano as diversas possibilidades existentes em relação à apresentação de textos.

\section{Legibilidade e tipografia para crianças}

Um livro didático deve, por definição, ser um livro de confortável leitura, isso é, que exija o mínimo de esforço por parte da criança para decodificar o seu conteúdo. Sendo assim, antes de tratar especificamente do caso da tipografia para crianças, é necessário o esclarecimento de alguns parâmetros a respeito da legibilidade e leiturabilidade da tipografia. As denominações legibilidade (legibility) e leiturabilidade (readability) são facilmente confundidas e usadas erroneamente. Sabese que, em momento algum, tais termos são sinônimos, podendo um texto ser considerado de baixa leiturabilidade e legível. Porém, quando ele é ilegível, a sua leiturabilidade também é altamente comprometida. Segundo o tipógrafo Walter Tracy, legibilidade refere-se à clareza de caracteres isolados, e sua medida é a velocidade com a qual eles são reconhecidos. A leiturabilidade, por outro lado, está relacionada ao conforto visual e é um requisito importante para textos longos (Tracy 2003 [1986]: 31). 


\section{Projetos e fontes produzidos para crianças}

Paulo Heitlinger (2007) afirma que um grande problema da educação infantil é a falta de ferramentas próprias, o que significa que "faltam fontes adequadas às capacidades cognitivas e motoras das crianças" (Heitlinger, 2007: 15). Ao questionar qual seria a fonte mais adequada para a fase de aquisição das escritas, muitos podem ser os palpites. $O$ fato é que há uma enorme diferença entre fonte para crianças e fonte com aspecto infantil. A preocupação em relação às necessidades da criança no aprendizado e o que é possível fazer para ajudá-la nesse processo está em crescente expansão.

As equipes de pesquisa descritas a seguir se empenharam em tentar descobrir uma fonte que atendesse às muitas das exigências do mundo infantil. Alguns tiveram uma fonte como resultado final - Sassoon e Flora.

\section{O projeto Kidstype}

Há disponível na internet um projeto em andamento chamado "Typographic Design For Children" (Design Tipográfico Para Crianças), também conhecido por "Projeto KIDSTYPE". Um grupo de quatro pesquisadores sob liderança de Sue Walker, professora do departamento de Tipografia e Comunicação Gráfica da University of Reading da Inglaterra, constituído pela mesma e por Linda Reynolds, Nicola Robson e Nadja Guggi tentou definir o que seria necessário para facilitar o processo de leitura e escrita das crianças, descobrindo a opinião destas. Para isso, levou-se em consideração opiniões de especialistas (designers/editoras) e crianças - o que elas pensam sobre as fontes e quais palavras são usadas para descrevê-las. Também foram feitas análises minuciosas para ver quantos e quais são os tipos de erros que os leitores jovens cometem durante a leitura.

Sobre a fonte ter ou não serifa para as crianças, chegou-se à conclusão de que, apesar das crianças notarem certa diferença no aspecto do tipo, tal fator não influencia na leitura. Apesar disso, professores alfabetizadores preferem fontes sem serifa pela simplicidade da forma.

Durante os testes, as crianças estavam cientes de que havia dois tipos de representação das letras a e g. Algumas delas fizeram a observação de que a e $\mathbf{g}$ de um andar ( figuras 1 e 2) é o que se escreve e que a e $\mathbf{g}$ ( figuras 2 e 3 ) de dois andares é o que se lê. Outras relataram que apesar de letras de dois andares serem mais difíceis de ler, isso não afeta o desenvolvimento da leitura. Os pesquisadores chegaram à conclusão de que é mais importante escolher fontes nas quais os caracteres se apresentem bem diferentes, principalmente as letras a, $\mathbf{g}$ e $\mathbf{o}$. É o caso da Gill Sans (figura 3), mas não da Futura (figura 1) e Avant Garde ou da Helvetica (figura 2).

Figura 1: Futura, fonte com caracteres a e $\mathbf{g}$ com um andar, o que torna $\mathbf{a}, \mathbf{g}$ e o muito parecidos.

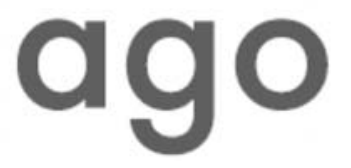

Figura 2: Helvetica, fonte com caractere a com dois andares e $\mathbf{g}$ com um andar, o que torna $\mathbf{a}, \mathbf{g}$ e o pouco diferentes.

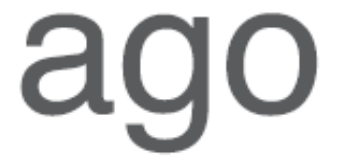

Figura 3: Gill Sans, fonte com caracteres a e $\mathbf{g}$ com dois andares, o que torna $\mathbf{a}, \mathbf{g}$ e o muito

$$
\text { diferentes. }
$$

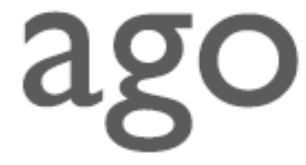

\section{Sassoon}

Segundo Sassoon e Williams, em seu guia descritivo sobre a família tipográfica Sassoon, tendências e necessidades especiais das crianças as fazem escolher por fontes sem inclinações, sem serifas nos topos das letras e com serifas nas linhas de base, o que ajuda a agrupar as letras em palavras, dando unidade a estas. Outros aspectos relevantes são: limpeza, miolos abertos, e o comprimento levemente acentuado das ascendentes e descendentes para melhor definir a forma 
da letra. Sassoon e Williams afirmam que crianças precisam de letras amigáveis e de fácil reconhecimento, resultantes de suas formas bem definidas.

A lista de caracteres da fonte Sassoon para crianças inclui caracteres em posições alternativas do teclado, havendo a possibilidade de escolher entre dois desenhos da letra " $\mathrm{k}$ ", por exemplo, como é mostrado na figura 4.

Figura 4: Quadro de glifos da fonte Sassoon Primary

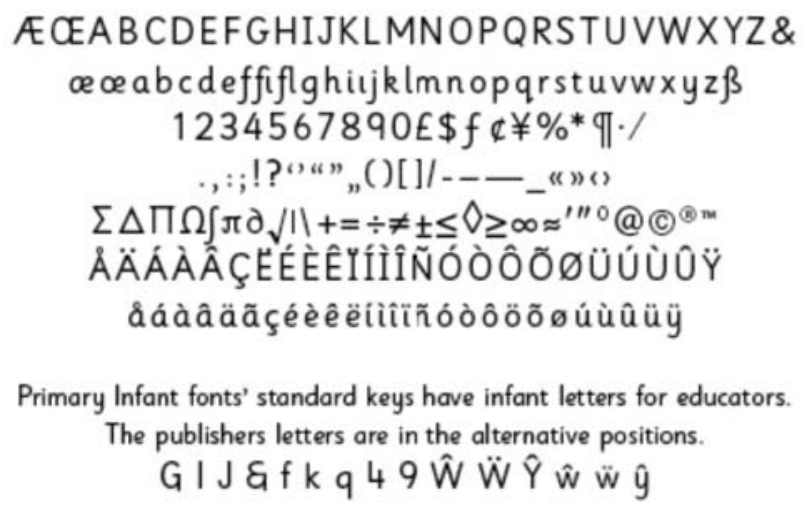

Fabula

Esta fonte foi desenvolvida por Vincent Connare, também criador da Comic Sans, com a finalidade de chegar a uma tipografia para ser utilizadas em livros de fábulas infantis na internet.

Segundo Walker et al. (2007), destacam-se nesta fonte as descendentes e ascendentes longas, que facilitam a identificação dos caracteres, o ar informal — ela não é rígida como as fontes encontradas normalmente para textos - a presença de diferenças no desenho de letras que normalmente são confundidas pelas crianças e as formas inusitadas para alguns caracteres.

Figura 5: Fonte Fabula (http://www.kidstype.org)

\title{
abcdefghijklmn \\ opqrstuvwxyz \\ ABCDEFGHIJKLMN \\ OPQRSTUVWXYZ \\ 0123456789
}

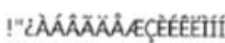

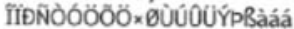

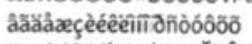

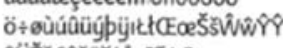

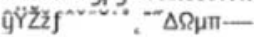

É possível notar grande semelhança entre a fonte Fabula e a Sassoon. Ambas possuem serifas ou prolongamentos somente na linha de base dos caracteres e apresentam ascendentes e descendentes longas. O que as torna formalmente distintas é o desenho da letra "a", os terminais arredondados da Fabula, e os prolongamentos mais longos da Sassoon.

\section{O projeto Didactica}

Didactica é uma fonte para livros didáticos infantis para crianças de 7 a 8 anos que estão em fase de alfabetização (figura 6). Decidiu-se pelo nome Didactica principalmente por ser uma fonte para ser aplicada em livros didáticos infantis e por ter como objetivo ser uma ferramenta no auxílio da alfabetização. Optou-se pela grafia com 'c' como referência às origens da língua portuguesa, e pela exclusão do acento para possibilitar maior compatibilidade na denominação dos arquivos digitais.

Figura 6: Conjunto de caracteres da fonte Didactica 


\section{ABCDEFGHIJKLMNOPQRSTUVXYZÇ abcdefghijklmnopqrstuxyzç 01234567890 "" ".:.:!?--_ áàâãã éêêe íîï óòõöô úùüû ÁÀÂÃÃ ÉÈÊË ÍİÎİ ÓÒÖÔ ÚU̇ÜÛ}

\section{Os caracteres e suas proporções}

As proporções da fonte didática foram baseadas análises das fontes Sassoon (figura 7) e Fabula (figura 8).

A largura dos tipos e a altura $x$ são iguais às das fontes Sassoon e Fabula. A altura das capitulares é menor que a das ascendentes para que as letras em caixa-alta que possuem acentos não invadam a linha superior quando aplicadas em textos, um diferencial em relação às outras duas fontes. As ascendentes são maiores que as descendentes pois essas são mais importantes no reconhecimento das letras (Cheng, 2006). As proporções demonstradas nas figuras foram obtidas a partir da medida " $x$ ", correspondente à largura de uma haste de cada uma das fontes.

Figura 7: Proporções da fonte Sassoon.

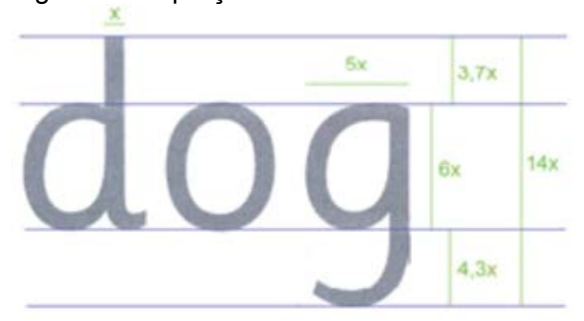

Figura 8: Proporções da fonte Fabula

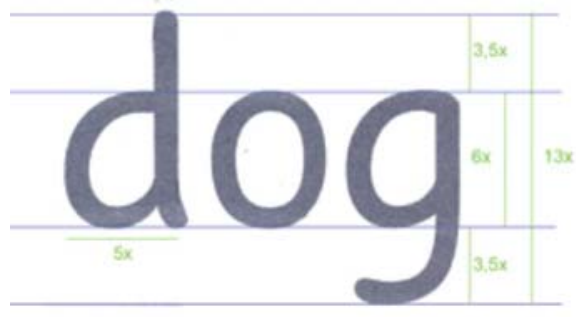

Figura 9: Proporções da fonte Didactica

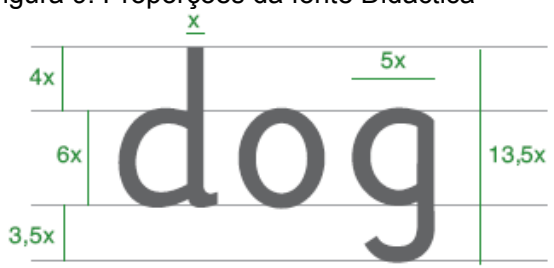

Como é possível notar, as letras com formas mais circulares (o, c, e, p, etc.) ultrapassam a altura $\mathrm{x}$ e a linha de base. Se tivessem a mesma altura das letras mais quadradas (x, z, etc.), as circulares pareceriam menores. (figura 10)

Figura 10: proporções da fonte Didactica 


\section{Infodesıgn}

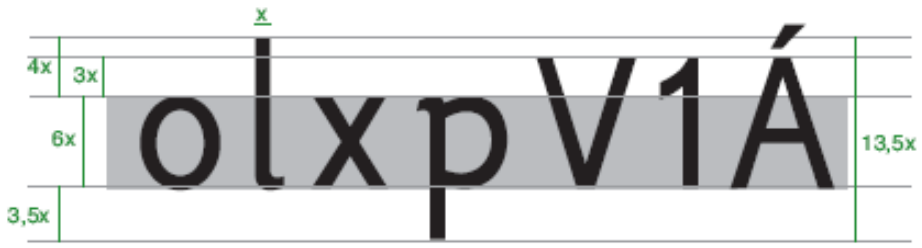

\section{Teste de aplicabilidade}

Concluído o desenvolvimento de uma primeira versão da fonte, foi realizado um teste de aplicabilidade. O teste envolveu a substituição das fontes Helvetica e Optima, presentes em duas páginas de texto do livro Português: uma proposta para o letramento - volume 1 (Soares 1999, figura 11) pela Didactica (figura 12), e a comparação das novas páginas com as páginas originais. As variações de itálico e negrito para a fonte Didactica foram simuladas.

Figura 13: Páginas originais do livro Português: uma proposta para o letramento - volume 1.

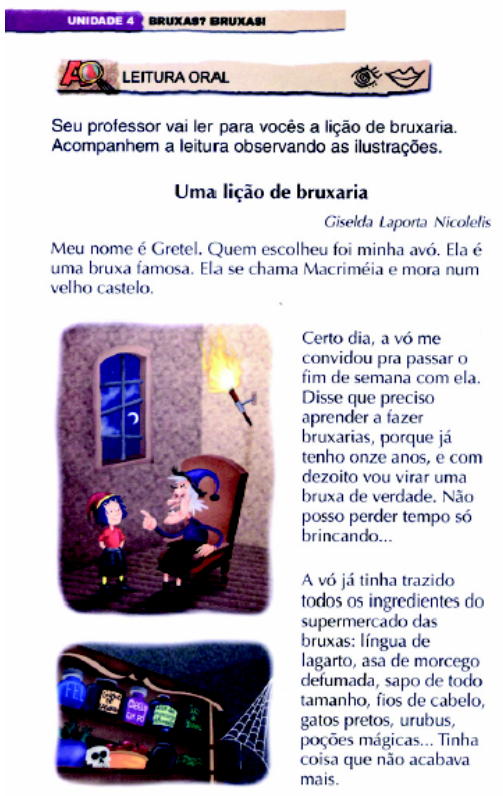

164
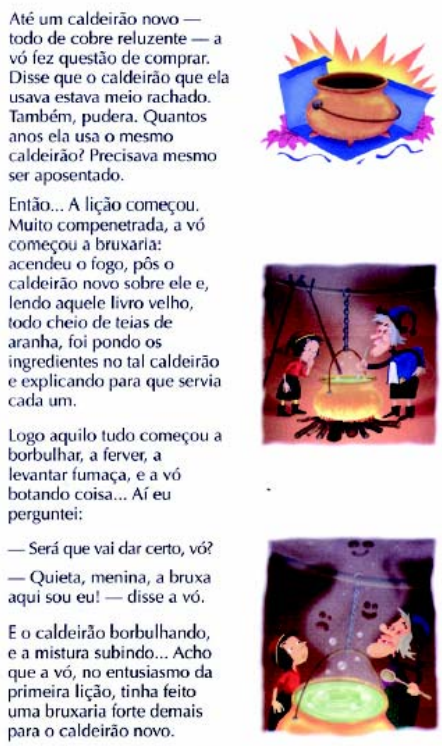

borbulhar, a ferver, a

botando coisa... Aí eu

pergunte: aqui sou eu! - disse a vó.

E o caldeirão borbulhando, uma bruxaria forte demais para o caldeirão nov

165 e

Figura 12: Páginas do livro Português: uma proposta para o letramento - volume 1 utilizando a fonte Didática. 

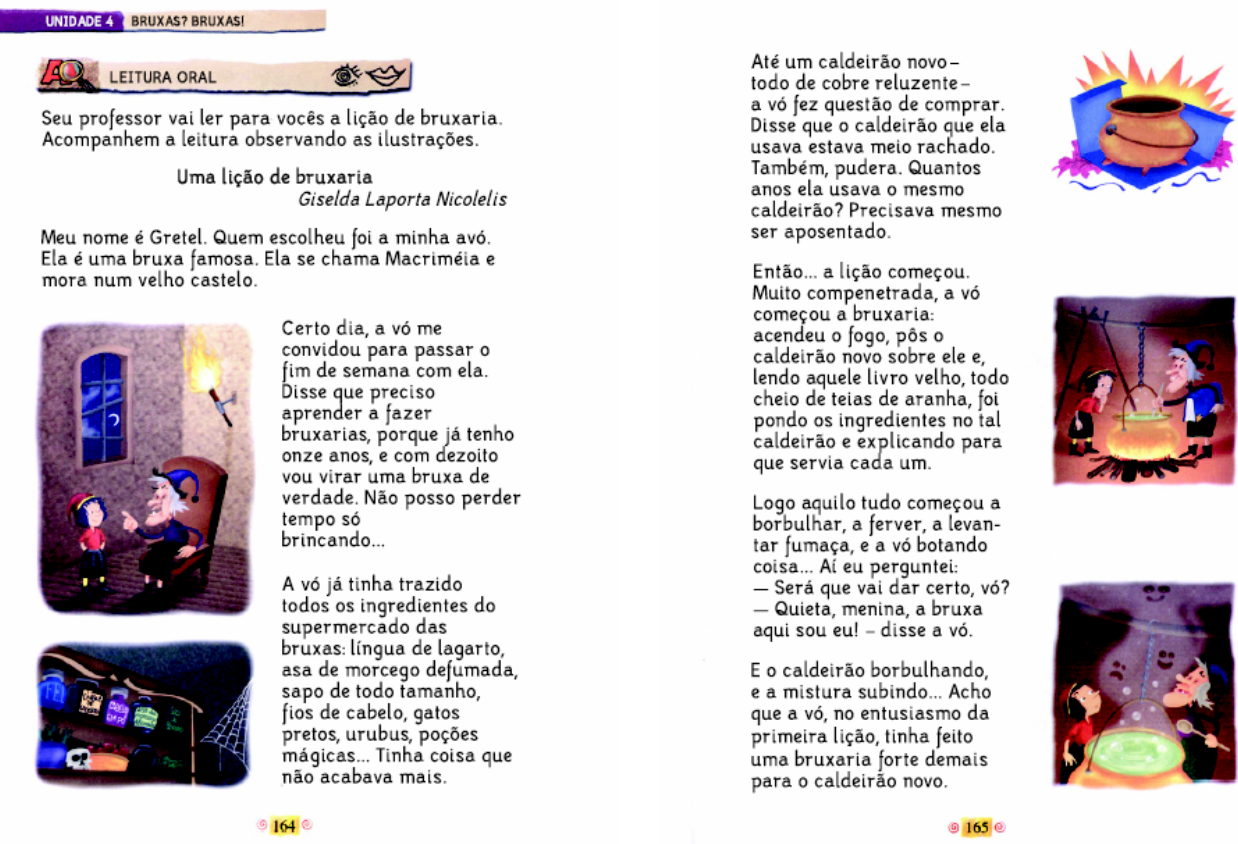

๑165อ

\section{Conclusão}

Através da pesquisa realizada, foi possível chegar a uma fonte com características próprias, adequada para o público infantil, e que pode ser aplicada em textos longos e curtos. Trata-se de uma fonte sem serifa e sem variações de espessura, com estrutura romana e que, ao mesmo tempo, possui traços cursivos. Crianças, durante a alfabetização, entram em contato com diferentes formas de escrita, como a letra de forma e a letra de mão. A mistura harmônica desses dois estilos resultou numa fonte que supomos ser bastante legível, com boa leiturabilidade, e apta para ser aplicada em textos longos. Algumas características a serem destacadas são:

- Ascendentes e descendentes mais longas do que as de fontes comumente utilizadas em livros infantis, como Helvetica, Optima, Futura, etc.

- Diferenciação entre caracteres que são propícios a confusões, como b, p, q e d, e I (ele minúsculo), I (i maiúsculo) e 1 (figura 13).

Figura 13: Desenhos diferentes para os caracteres I, I e 1 na fonte Didactica

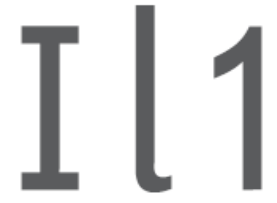

- Distinção entre os caracteres $\mathbf{a}, \mathbf{g}$ e o que também podem ser confundidos pelas crianças. $\mathrm{Na}$ fonte Didactica, o a tem estrutura romana (dois andares), enquanto o $\mathbf{g}$ se assemelha à itálica (um andar). Quando crianças foram questionadas por Walker (2005) sobre qual é a diferença notada por elas entre o a de dois andares e o a de um andar, elas responderam que o $\mathbf{a}$ e $\circ \mathbf{g}$ de dois andares são o que elas lêem. Sendo esta uma fonte projetada para a leitura, a escolha pelo a de dois andares se mostra mais pertinente. Decidiu-se por diferenciar o $\mathbf{a}$, pois este em itálico se assemelha mais ao desenho do o do que o $\mathbf{g}$ (Figura 14). 
Figura 14: Comparação entre os caracteres a, g e o das fontes Lucida Fax na versão itálica (topo) e Didactica (abaixo)

\section{$\operatorname{ag}$ og 90 ag og go}

- Prolongamento de algumas letras remetendo ao desenho das letras cursivas.

- Hastes sem variações de espessuras, com exceção de ajustes ópticos, visualmente mais próximas aos traços uniformes obtidos a partir da ponta de caneta no papel e giz no quadro-negro e das letras cursivas presentes nas cartilhas.

- Letra e arredondada e com barra inclinada, como nas letras cursivas, para dar um aspecto mais informal à fonte.

- Tipografia sem serifa, preferida pelos professores..

- Proporções e espaçamento otimizados para aplicação em corpo 18, ( sendo este o tamanho recomendado por Burt (1959, tabela 1) para crianças com oito anos de idade.

Após o teste de aplicabilidade foi possível concluir que Didactica possui boa legibilidade quando aplicada em corpo 18, mas que a fonte ainda apresenta pequenos problemas de espaçamento, $\mathrm{e}$ que sua aplicabilidade seria maior se os estilos itálico e bold fossem desenvolvidos. Para a continuidade deste projeto, também seria adequada a ampliação do conjunto de caracteres, incluindo diacríticos utilizados em outras línguas.

\section{Referências}

ABUD, Maria José Milharezi 1987. O Ensino da leitura e da escrita na fase inicial da escolarização. São Paulo: EPU.

CAGLIARI, Luiz Carlos 2003. Alfabetização e lingüística. São Paulo: Scipione.

CÂMARA BRASILEIRA DO LIVRO 2002. Produções e vendas do setor editorial brasileiro. Relatório Anual.

CHENG, Karen 2005. Diseñar tipografia. Barcelona: Gustavo Gili.

COUTINHO, Solange Galvão e GUSMÃO, Gustavo 2004. AlphaBetica: uma família tipográfica para leitores iniciantes. Monografia (Bacharelado em Design) - Universidade Federal de Pernambuco,.

COUTINHO, Solange Galvão e SILVA, José Fabio Luna da 2007. Linguagem visual em livros didáticos infantis. Disponível em: <http://www.unifacs.br/anpap/autores/168.pdf>. Acesso em: 19 abril.

FARIAS, Priscila 2001 [1998]. Tipografia digital: o impacto das novas tecnologias. Rio de Janeiro: $2 A B$,

HEITLINGER, Paulo 2007. 'Qual é a fonte mais apropriada para criança?'. Cadernos de Tipografia, n. 2, p. 15-20. Disponível em: <http://www.tipografos.net/cadernos/cadernos-2.pdf>. Acesso em: 13 out. 2007

SASSOON, Rosemary e WILLIAMS, Adrian 2000. Why Sassoon? Disponível em: <http://www.clubtype.co.uk/Why\%20Sassoon.pdf>. Acesso em: 21 out. 2007.

SIMÕES, Vera Lucia Blanc 2000. 'Histórias infantis e aquisição de escrita'. São Paulo em Perspectiva, v. 14, n. 1,. Disponível em:

<http://www.scielo.br/scielo.php?script=sci_arttext\&pid=S0102-8839200000010000

\&lng=en\&nrm=iso>. Acesso em: 03 Set. 2007.

SOARES, Magda 1999. Português: uma proposta para o letramento - volume 1. São Paulo: Moderna. 
SOARES, Wander. O livro didático e a educação. 2002. Disponível em:

$<$ http://abrelivros.org.br/abrelivros/texto.asp?id=15 >

TRACY, Walter 2003 [1986]. Letters of credit: a view of type design. Boston: David R. Godine.

WALKER, Sue; REYNOLDS, Linda; ROBSON, Nicola e GUGGI, Nadja. Typographic Design For Children. Disponível em: <www.kidstype.org>. Acesso em: 05 Maio 2008.

WALKER, Sue 2005. The songs the letters sing: typography and children's reading. Reading: National Centre for Language and Literacy.

Paula Cristina Casarini, Bacharel, Centro Universitário SENAC.

Possui graduação em Design Gráfico pelo Centro Universitário SENAC (Jun/2008). Atualmente é assistente de arte na Editora Nobel.

paulacasarini@hotmail.com

Priscila Lena Farias, Doutora, Centro Universitário SENAC e USP.

Coordenadora do Programa de Pós-graduação em Design do Senac-SP e professora do curso de design da FAUUSP. Autora do livro Tipografia Digital (2AB) e de diversos artigos sobre tipografia, design e semiótica. Organizadora dos livros Fontes Digitais Brasileiras (Rosari) e Advanced Issues in Cognitive Science and Semiotics (Shaker Verlag).

priscila.farias@pq.cnpq.br 